\title{
Microstructure, Mechanical Properties, and Martensitic Transformation in NiTi Shape Memory Alloy Fabricated Using Electron Beam Additive Manufacturing Technique
}

\author{
Jan Dutkiewicz, Łukasz Rogal, Damian Kalita, Jakub Kawałko, Marek Stanisław Wegglowski, Krzysztof Kwieciński, Piotr Śliwiński, \\ Hubert Danielewski, Bogdan Antoszewski, and Eduard Cesari
}

Submitted: 26 May 2021 / Revised: 31 August 2021 / Accepted: 5 September 2021 / Published online: 15 October 2021

\begin{abstract}
The electron beam additive manufacturing (EBAM) method was applied in order to fabricate rectangularshaped NiTi component. The process was performed using an electron beam welding system using wire feeder inside the vacuum chamber. NiTi wire containing 50.97 at.\% Ni and showing martensitic transformation near room temperature was used. It allowed to obtain a good quality material consisting of columnar grains elongated into the built direction growing directly from the NiTi substrate, which is related to the epitaxial grain growth mechanism. As manufactured material showed martensitic and reverse transformations diffused over the temperature range from -10 to $44{ }^{\circ} \mathrm{C}$, the applied aging at $500^{\circ} \mathrm{C}$ moved the transformation to higher temperatures and transformation peaks became sharper. The highest recoverable strain of about $3.5 \%$ was obtained in the as-deposited sample deformed along the deposition direction. In the case of deformation of the alloy aged at $500{ }^{\circ} \mathrm{C}$ for $2 \mathrm{~h}$, the formation of martensite occurs at significantly lower stress; however, at about $2.5 \%$ the stress begins to increase gradually and only a small shape recovery was observed due to a higher martensitic transformation temperature. In situ SEM tensile deformation in the direction perpendicular to deposition direction showed that the martensite began to appear at the surface of the sample and at the grain boundaries due to heterogeneous nucleation. In situ studies allowed to determine the following crystallographic relationships between B2 and B19' martensite: $(100)_{\mathrm{B} 2} \|(100)_{\mathrm{B} 19}$, and (100) $\mathrm{B} 2\left\|(011)_{\mathrm{B} 19} ;(011) \mathrm{B} 2\right\|(001)_{\mathrm{B} 19}$, and $(011)_{B 2} \|(11 \overline{1})_{B 19^{\prime}}$. Samples aged at $500{ }^{\circ} \mathrm{C}$ exhibited fully austenitic microstructure; however, with increasing degree of deformation, the formation of martensite was observed. The majority of needles were tilted about $45^{\circ}$ with respect to the tensile direction, and the presence of type $I$ (11 $\overline{1})$ invariant twin boundaries was observed at higher degrees of deformation.
\end{abstract}

Keywords additive manufacturing, in situ studies, martensitic transformation, NiTi, shape memory alloys, superelasticity

\section{Introduction}

NiTi shape memory alloys (SMAs) found a wide range of applications in the industry, including aerospace (tubing couplings, actuators), medical (stents, orthodontic wires, bone fixation plates), and automotive (valves, actuators) (Ref 1, 2). This is associated with the unique functional properties exhibited by this material such as shape memory (SM) and

Jan Dutkiewicz, Lukasz Rogal, and Damian Kalita, Institute of Metallurgy and Materials Science, PAS, 25, Reymonta St, 30-059 Krakow, Poland; and Jakub Kawalko, Academic Centre for Materials Nanotechnology, AGH, 30, Mickiewicza Av, Kraków, Poland; Marek Stanisław Wegglowski, Krzysztof Kwieciński, and Piotr Śliwiński, Łukasiewicz-Institute of Welding, Błogosławionego Czesława 16-18, 44-100 Gliwice, Poland; Hubert Danielewski and Bogdan Antoszewski, Laser Research Centre, Faculty of Mechatronics and Mechanical Engineering, Kielce University of Technology, Al. Tysiąclecia P.P. 7, 25-314 Kielce, Poland; and Eduard Cesari, Department of Physics, University of Balearic Islands, E07122 Palma de Mallorca, Spain. Contact e-mail: j.dutkiewicz@imim.pl. superelastic (SE) properties, low stiffness, damping behavior, high corrosion resistance, and biocompatibility. The shape recovery observed for the NiTi alloys results from the occurrence of the reversible martensitic transformation (MT) that takes place between the B2 austenite and B19' martensite. The wide interest of the industry in the NiTi alloys is limited by difficulties in fabrication of elements from this material due to the high reactivity of melted alloy, which results in the formation of Ti-rich compounds like $\mathrm{TiC}$ or $\mathrm{Ti}_{4} \mathrm{Ni}_{2} \mathrm{O}_{\mathrm{x}}$, degrading their functional properties. Another problem is associated with the low ductility of NiTi alloys, resulting in difficulties in processing and machining (Ref 3 ). These drawbacks limit the geometries of the fabricated elements mainly to the rods, wires, bars, tubes, or sheets. In recent years, additive manufacturing (AM) technology becomes a promising approach to direct fabrication of NiTi parts with complex geometries, which is difficult or even impossible to obtain in the conventional plastic deformation methods (Ref 3 ). In the AM process, the elements are reconstructed, based on 3D CAD models, using powder or wire feedstock, which is melted using highly focused laser or electron beam. This provides great opportunities of fabrication of the parts with complex shapes, internal channels, internal porosity, or near-net-shape elements (Ref 4).

Recently, a few different powder-based AM techniques were applied in the fabrication of elements from NiTi alloys, e.g., selective laser melting (SLM) (Ref 3), electron beam melting (EBM) (Ref 5), direct energy deposition (DED) (Ref 6), or laser-engineered net shaping (LENS) (Ref 7). The effect of the 
processing parameters such as laser power, scanning velocity, layer thickness, or energy input on the microstructure, transformation behavior, and mechanical properties of the fabricated parts were investigated earlier (Ref 8-10). The microstructure of the AM-fabricated NiTi alloys consists usually of columnar grains elongated into the built direction, which was found to be associated with the epitaxial growth mechanism that takes place during the deposition. This also resulted in strong [001] texture along the build direction frequently reported for the AMmanufactured NiTi parts (Ref 7, 11). However, in order to fabricate elements exhibiting high density, high-dimensional accuracy, and low fraction of defects, the deposition has to be conducted in a previously specified process window, e.g., in the case of SLM method full-density NiTi parts may be obtained at energy input of about $55 \mathrm{~J} / \mathrm{mm}^{3}$ (Ref 3 ). The application of lower energy densities typically results in incomplete melting of the powder particles causing the formation of irregular porosity (Ref 10). On the other hand, the use of high energy densities leads to the formation of large $\mathrm{Ni}_{4} \mathrm{Ti}_{3}$ particles and higher level of impurities (Ref 12, 13). Wang et al. (Ref 8) showed that the change in the fabrication conditions not only affects the microstructure of the alloy, but also the transformation temperature and shape memory properties. This was associated with the changes in the chemical composition of the materials with the energy input as a result of $\mathrm{Ni}$ evaporation in melt pool, reported also by other authors (Ref 13). Ma et al. (Ref 14) utilized this effect for fabrication of NiTi parts with the location-dependent shape memory response. In this case, different areas of the part exhibited varied transformation temperatures due to different parameters used during the fabrication by SLM. The superelastic response of the AMfabricated parts was registered for Ni-rich alloys, e.g., $\mathrm{Ni}_{50.8} \mathrm{Ti}_{49.2}$ fabricated by SLM (Ref $15-17$ ), $\mathrm{Ni}_{51.2} \mathrm{Ti}_{48.8}$ by EBM (Ref 11), or $\mathrm{Ni}_{50.1} \mathrm{Ti}_{49.9}$ by LENS (Ref 7 ). The superelasticity of NiTi alloys in the as-deposited state is moderate - they exhibited a recoverable strain of about 2-3\% (Ref 16-18). This results mainly from the wide temperature range of the martensitic transformation observed for alloys in as-deposited state, associated with the formation of Ni-rich precipitations during the deposition and slight fluctuation of chemical composition of the matrix (Ref 16). Therefore, the superelastic properties of additively manufactured NiTi alloys may be enhanced by an additional heat treatment, e.g., Seadi et al. (Ref 16) showed the increase of recoverable strain of SLM-manufactured NiTi from 3.2 to $5.5 \%$ for solution-treated and aged at $600{ }^{\circ} \mathrm{C}$ sample. The positive effect of postprocessing heat treatment was also reported in other works (Ref 17, 19). On the other hand, Moghaddam et al. (Ref 15) showed that by controlling the microstructure and texture during the SLM deposition is possible to fabricate elements exhibiting superior recoverable strain of $5.6 \%$ without the application of additional heat-treatment.

Recently, a new additive manufacturing technology utilized a wire as an additive material, instead of powder, what found the application in fabrication of metallic components from different materials such as aluminum alloys (Ref 20), titanium alloys (Ref 21), nickel alloys (Ref 2), and steels (Ref 23). Depending on the energy source used for the metal deposition, the wire-based AM may be classified into three groups, such as wire and laser additive manufacturing (WLAM), wire and arc additive manufacturing (WAAM), and electron beam additive manufacturing (EBAM) (Ref 24). Those methods offer the possibility of fabrication of larger components in comparison with the powder-based methods, higher material efficiently and much higher deposition rates, e.g., in the case of EBAM, it may reach up to $300 \mathrm{~g} / \mathrm{min}$, whereas for SLM it is only about 2-4 g/ min (Ref 24, 25). In the case of NiTi alloys, the application of wire-based methods may be favorable considering the fact that the NiTi wires are commercially available in contrast to the highly expensive atomized powders. However, the literature data regarding the application of such methods in fabrication of elements from NiTi alloys are very limited. In recent two years, a few papers concerning the use of WAAM technique were published (Ref 26-29). Wang et. al (Ref 26) used Ni and $\mathrm{Ti}$ wires in order to manufacture Ni-rich NiTi parts by WAAM, which exhibited anisotropic microstructure with increased amount of $\mathrm{Ni}_{4} \mathrm{Ti}_{3}$ and decreased amount of $\mathrm{Ni}_{3} \mathrm{Ti}$ precipitations from lower to upper region. These differences in the phase composition of the material resulted in changes of the martensitic transformation temperature along the height of the sample. Zeng et al. (Ref 27) showed that the application of a dedicated NiTi wire resulted in more homogenous microstructure consisting of elongated grains into the built direction, similar to what is observed in materials deposited using powder feedstock. The fabricated part exhibited a high relative density and low defects density, which resulted in relatively high ductility (elongation up to $17 \%$ ). Nevertheless, the microstructure of the deposited elements is highly dependent on the applied process parameters, e.g., Wang et al. (Ref 28) reported austenite grain coarsening and increase in size of $\mathrm{Ni}_{4} \mathrm{Ti}_{3}$ precipitations with the increasing deposition current in $\mathrm{NiTi}$ fabricated by the WAAM process. As a result, the increase in the transformation temperature and decrease in the recoverable strain from 3.2 to $2.2 \%$ with the increasing deposition current from $80 \mathrm{~A}$ to $120 \mathrm{~A}$ were registered. Similar superelastic properties of the WAAM-deposited element, with the $2.7 \%$ of recoverable strain, were reported by Zeng et al. (Ref 27).

Although the application of WAAM process in the fabrication superelastic elements from NiTi alloys seems to be promising, other wire-based methods like EBAM may provide even better characteristics of as-deposited parts. Here, the essential may be the atmosphere used during the deposition. In the case of WAAM method, the deposition is conducted under the shielding gas, which may lead to pick up the impurities due to a high reactivity of Ti. The formation of Ti-rich phases, such as $\mathrm{Ti}_{4} \mathrm{Ni}_{2} \mathrm{O}$, significantly changes $\mathrm{Ti} / \mathrm{Ni}$ ratio and affects the phase transformation temperatures as well as functional and mechanical properties of the fabricated parts (Ref 30). In the case of SLM method, the application of the shielding gas was insufficient, and in order to obtain the materials exhibiting good ductility, the process has to be conducted in protective atmosphere inside the building chamber (Ref 8, 31). On the other hand, in the EBAM method the deposition process is conducted in high vacuum, due to the use of an electron beam as an energy source. It may further decrease the amount of impurities in as-deposited elements and enhance their functional properties. This technique was used for the first time in the fabrication of NiTi alloys in our previous work (Ref 7). The produced preliminary element in the as-deposited state showed homogenous microstructure and high recoverable strain of nearly $3 \%$ in the compression mode. In this study, a larger NiTi element was fabricated with the application of EBAM technique in order to determine its mechanical and functional properties in a tensile mode. The aim of the presented work was also to perform investigation of the martensitic transformation behavior during the in situ SEM tensile test applying the EBSD 
technique which allows to determine texture changes, twinning modes, and determination of the crystallographic relationship between formed martensite and austenite.

\section{Experimental}

\subsection{Material Fabrication}

The EBAM method was applied in order to fabricate the NiTi component with rectangular shape and the following dimensions: height $10 \mathrm{~mm}$, thickness $15 \mathrm{~mm}$, and length 90 $\mathrm{mm}$, as shown in Fig. 1. The process was performed using an electron beam welding system XW150:30/756 (Cambridge Vacuum Engineering Ltd.). The device is equipped with electron beam maximum powder of $30 \mathrm{~kW}$ and feeder inside the vacuum chamber. NiTi wire of $1 \mathrm{~mm}$ thick with composition of 50.97 at.\% Ni, 0.22 max at.\% $\mathrm{C}$ and $\mathrm{Ti}$ balance, delivered by SMATEC company, Belgium, was used during the deposition. A NiTi sheet with thickness of $3 \mathrm{~mm}$ and chemical composition: 50.74 at.\% Ni, 0.12 at.\% $\max \mathrm{C}$, Ti balance, delivered by SMATEC was used as an substrate. Based on preliminary studies, the set of the following parameters was applied during the fabrication process: accelerating voltage 60 $\mathrm{kV}$, beam current $15 \mathrm{~mA}$, feeding angle $30^{\circ}$, wire feed speed $1000 \mathrm{~mm} / \mathrm{min}$, and traveling speed $2000 \mathrm{~mm} / \mathrm{min}$. The process was conducted in vacuum.

\subsection{Material Characterization}

The microstructural observations and electron backscatter diffraction measurements were conducted using a scanning electron microscope (SEM) FEI Versa 3D equipped with an EDAX Hikari CCD camera. The in situ deformation studies were performed using a Kammrath\&Weiss $5 \mathrm{kN}$ tensile/compression stage. The dog-bone shape samples with cross section of $1 \times 2 \mathrm{~mm}$ and gauge length of $3 \mathrm{~mm}$ were prepared in an electrical discharge machine (EDM). The tensile testing was carried out at room temperature (RT) with constant strain rate of $10^{-3} \mathrm{~s}^{-1}$. A more detailed microstructural analysis was conducted using a transmission electron microscope (TEM) Tecnai G2 F20 Super Twin equipped with EDAX Apollo XP energy-dispersive $\mathrm{x}$-ray spectrometer (EDS). The thin foils for TEM observations were prepared by electropolishing of 100$\mu \mathrm{m}$-thick disks in an electrolyte containing $10 \mathrm{~mol} . \% \mathrm{HClO}-4$ in methanol (voltage $20 \mathrm{~V}$, temperature $-20{ }^{\circ} \mathrm{C}$ ). The phase transformation temperatures were investigated by differential

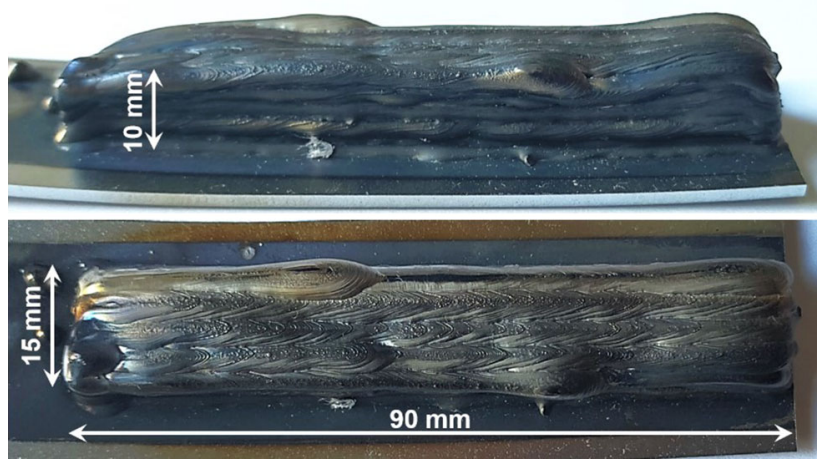

Fig. 1 Photograph of samples prepared by the EBAM method scanning calorimetry (DSC) technique using a Mettler DSC 823 instrument, with a cooling/heating rate of $10^{\circ} \mathrm{C} / \mathrm{min}$. The tensile tests were carried out using a Shimadzu Autograph AG$\mathrm{X}$ plus testing machine at $10^{-3} \mathrm{~s}^{-1}$ strain rate. The strain was measured using a video-extensometer TRViewX system. The tests were conducted at RT as well as at temperature $10{ }^{\circ} \mathrm{C}$ above the $A_{f}$ (specified by the DSC). The materials for the tensile tests were prepared by EDM in the form of dog-bone samples with the cross section of $1 \times 2 \mathrm{~mm}$ and gauge length of $5 \mathrm{~mm}$.

\section{Results and Discussion}

\subsection{Microstructure}

Figure 2 shows the optical microstructure of as-deposited part. It exhibits a high relative density without any evidence of

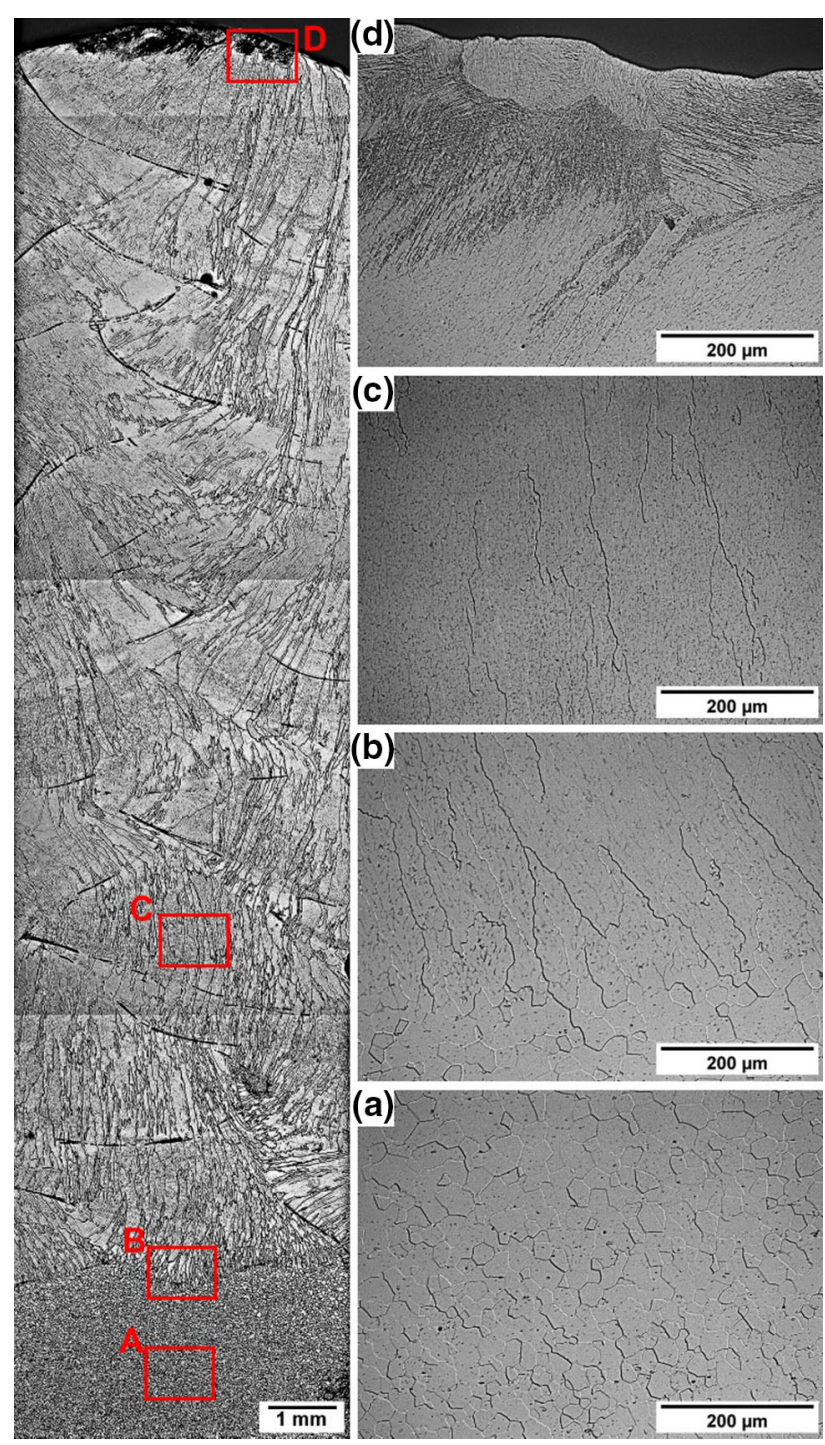

Fig. 2 Optical microstructure of the cross section of the asdeposited part: substrate (a), interface between the substrate and first deposited layer (b), region of columnar grains (c), and the upper region of the part (d) 
discontinuities along its entire height. In the bottom part of the micrograph (mark A), the equiaxed microstructure of the NiTi substrate may be observed. Next micrograph (marked as B) shows the interface between the substrate and the first deposited layer. It can be noticed that the equiaxed grains occurring in the substrate are in direct contact with the columnar grains elongated into the built direction. Furthermore, the thickness of the columnar grains corresponds to the size of the equiaxed ones, which is related to the epitaxial grain growth mechanism frequently reported for the additive manufactured materials (Ref 7, 11). The penetration depth of laser or electron beam is typically larger than the thickness of the deposited layer, which results in the partial re-melting of the previously deposited layers or substrate. Next, due to a high thermal gradient in the formed melt pool, the conditions for the epitaxial growth of columnar grains appear at the bottom of the melt pool (Ref 32). The columnar grains occur up to the top of the deposited parts as shown in Fig. 2. However, the direction of their growth slightly changes in the following layers as well as it departs from the built direction. This is associated with the local thermal flux inside the created melt pool from its center to the edge. As a result, only the grains growing in the center of the melt pool exhibit the growth direction along the built direction, whereas those away from the center are slightly tilted. A different microstructure was observed only in the upper layer, below $500 \mu \mathrm{m}$ from the top part, where the equiaxed grains existed. Similar behavior was observed for WAAM-fabricated NiTi part (Ref 29). Considering the microstructural nonhomogeneities observed also in the bottom layer in contact with the substrate and in the top layer, further investigations were conducted only for the center part of the element where the columnar microstructure occurred.

Figure 3 shows a TEM micrograph from the as-deposited EBAM sample. One can see a set of parallel martensite needles (some marked by white arrows) within the NiTi B2 austenite. However, $\mathrm{M}_{\mathrm{s}}$ temperature is below the RT; its formation is most probably due to stress introduced by bending of the thin sample within the microscope. The selected area diffraction pattern (SADP) taken from the central dark part of the image indicating reflecting orientation shows the [001] zone axis of the austenite grain (marked by A) and two of the [100] B19' zone axis in twin orientations marked by $\mathrm{M}$ and $\mathrm{T}$ in the indexing of the diffraction pattern in Fig 3 can be identified. The white line in the SADP crossing 000 and 011 reflection of martensite and twin is perpendicular to the twin boundary, indicating the $<011>$ type II twinning (marked by bright arrows in the micrograph and composed of parallel bright and dark twins) resulting from the invariant plane shear as suggested by Otsuka (Ref 33). The 001 martensite reflections may overlap with 040 $\mathrm{Ti}_{2} \mathrm{Ni}_{3}$ reflections as results from the diffraction pattern presented by Nishida and Wayman (Ref 34), and irregular particles marked by dark arrows suggest its presence.

The presence of such particles being nucleation sites of needles was observed in aged specimens where particles were identified using STEM microscopy and EDS microanalysis as shown in Fig. 4. They contain less titanium (46,5 at.\% Ti) being most probably $\mathrm{Ni}_{3} \mathrm{Ti}_{2}$ or $\mathrm{Ni}_{4} \mathrm{Ti}_{3}$ intermetallic phase. The content of titanium is lower than expected most probably due to a small size of particles, resulting in an additional signal from the matrix.

In Fig. 5, TEM micrograph shows a frequent martensitic plates in the austenite grain of the sample aged $2 \mathrm{~h} / 500{ }^{\circ} \mathrm{C}$. Few fine needles, much less frequent than in the as-prepared sample, give a weak twin reflections. Generally, orientation of [001] zone axis of austenite and [100] B19' zone axis is similar to that in Fig. 3; however, twin orientation gives rather weak diffraction spots most probably due to deflection of a thin sample. TEM studies did not show major differences concerning the presence of martensite in the as-prepared and aged samples due to uncontrolled deflection of thin samples, causing the formation of martensite above the $\mathrm{M}_{\mathrm{s}}$ temperature.

\subsection{DSC Studies}

Figure 6 shows the DSC curves of the alloy in the asdeposited (AD) state as well as after various aging times at $500{ }^{\circ} \mathrm{C}$. Based on these data, the following temperatures were determined: martensite start $\left(M_{s}\right)$, martensite finish $\left(M_{f}\right)$, austenite start $\left(A_{S}\right)$, austenite finish $\left(A_{f}\right)$, R-phase start $\left(R_{S}\right)$, and R-phase finish $\left(R_{f}\right)$ describing the beginning and end of the specific transformations. The temperatures are summarized in Table 1. The peaks observed for the AD material were diffused over a large temperature range; however, with increasing aging time they became sharper. After $30 \mathrm{~min}$ of annealing at $500{ }^{\circ} \mathrm{C}$, the thermal effects observed during the cooling (Fig. 6a) were split into two distinct parts. The first one, which occurred in the temperature range of about $10-25^{\circ} \mathrm{C}$, was associated with the R-phase formation, as was commonly observed for the aged Nirich NiTi alloys (Ref 35). The increasing aging time did not have an effect on both $R_{s}$ and $R_{f}$ temperatures, which is typical for the $\mathrm{B} 2 \rightarrow \mathrm{R}$ transformation. On the other hand, the temperatures of martensitic and reverse transformation gradu-
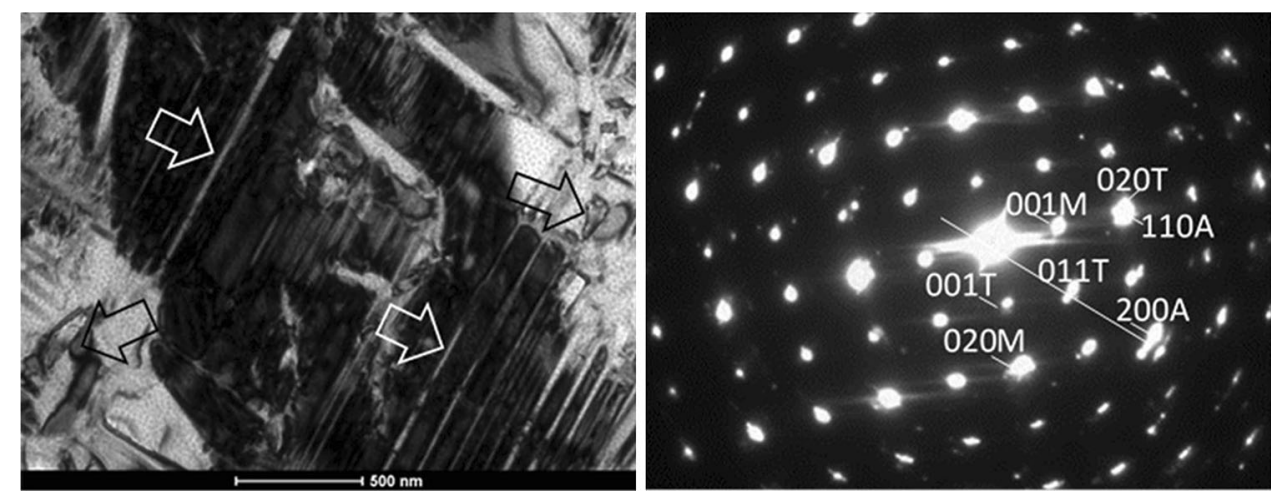

Fig. 3 TEM micrograph and SADP from the as-prepared sample by EBAM method. SAED was indexed according to [100] B19' and [001] austenite zone axis orientations. 
ally increase with annealing time. Similar behavior was also observed by other authors; for example, Khalil-Allafi et al. (Ref 36) show that the annealing of NiTi alloy at temperature of

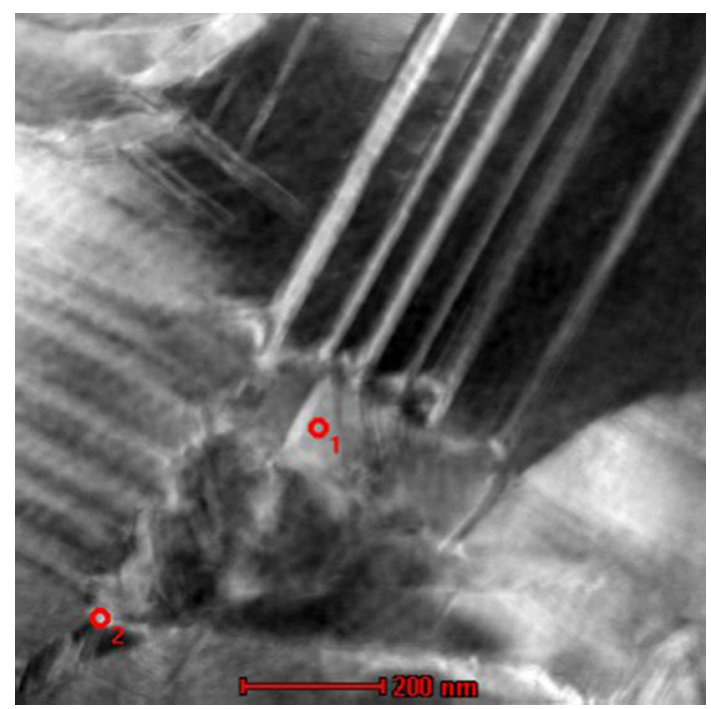

Fig. 4 STEM micrograph of the aged specimen with marked places of point analysis from particles containing less Ti (46.5 at.\%) where nucleation of needles took place.

$500{ }^{\circ} \mathrm{C}$ resulted in increase of transformation temperature due to the formation of $\mathrm{Ni}$-rich $\mathrm{Ni}_{4} \mathrm{Ti}_{3}$ precipitations, which causes $\mathrm{Ni}$ depletion in the matrix. Furthermore, the aging resulted also in the separation of the second thermal effect (associated with the martensitic transformation) into two different regions, which is especially visible for samples aged for $2 \mathrm{~h}$ or more. This phenomenon indicates a multi-stage martensitic transformation, and it is most probably associated with the large-scale microstructural heterogeneity, resulting from the different precipitation behavior between the grain boundary region and grain interior (Ref 37). Similarly, the two-stage reverse transformation was observed for the aged samples during

Table 1 Martensitic transformation temperatures of fabricated material in as-deposited (AD) state and after aging

\begin{tabular}{lllllll}
\hline State & $\boldsymbol{M}_{\boldsymbol{s}}$ & $\boldsymbol{M}_{\boldsymbol{f}}$ & $\boldsymbol{A}_{\boldsymbol{s}}$ & $\boldsymbol{A}_{\boldsymbol{f}}$ & $\boldsymbol{R}_{\boldsymbol{s}}$ & $\boldsymbol{R}_{\boldsymbol{f}}$ \\
\hline $\mathrm{AD}$ & -10 & -44 & -16 & 20 & $\ldots$ & \\
$500^{\circ} \mathrm{C} / 15 \mathrm{~min}$ & -6 & -30 & -4 & 25 & $\ldots$ & $\ldots$ \\
$500^{\circ} \mathrm{C} / 30 \mathrm{~min}$ & -6 & -45 & 12 & 36 & 25 & 11 \\
$500^{\circ} \mathrm{C} / 1 \mathrm{~h}$ & 0 & -34 & 24 & 45 & 26 & 10 \\
$500^{\circ} \mathrm{C} / 2 \mathrm{~h}$ & 6 & -22 & 29 & 48 & 26 & 13 \\
$500^{\circ} \mathrm{C} / 4 \mathrm{~h}$ & 11 & -14 & 33 & 49 & 26 & 15 \\
$500^{\circ} \mathrm{C} / 8 \mathrm{~h}$ & 16 & -7 & 36 & 51 & 26 & 17 \\
\hline
\end{tabular}
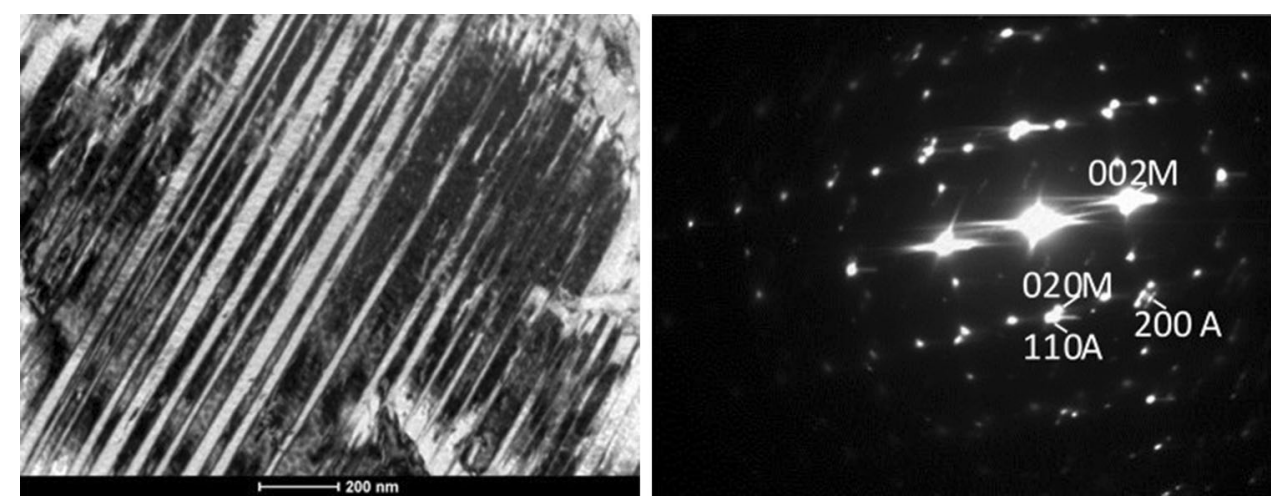

Fig. 5 TEM micrograph and SADP from the as-prepared sample by EBAM method aged $2 \mathrm{~h} / 500{ }^{\circ} \mathrm{C}$
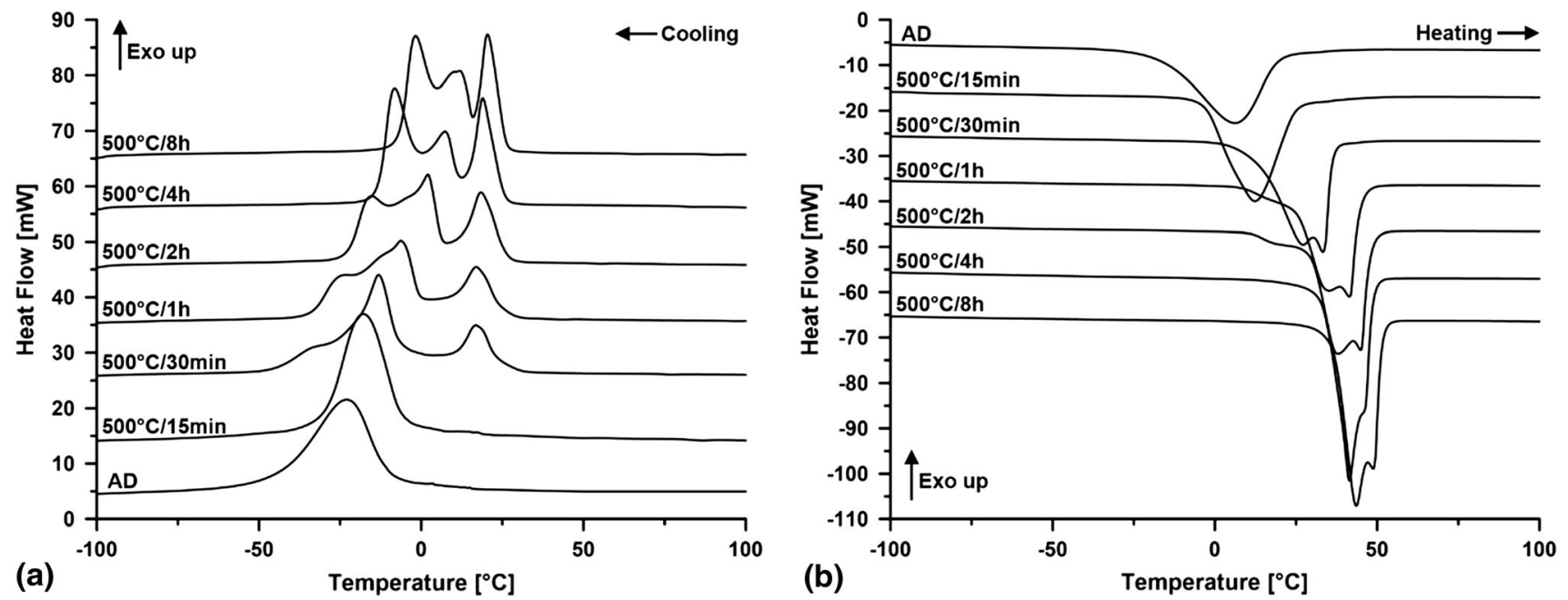

Fig. 6 DSC cooling (a) and heating (b) curves of as-deposited (AD) NiTi and after a various time of aging at $500{ }^{\circ} \mathrm{C}$ 
heating (Fig. 6b). As longer annealing time than $2 \mathrm{~h}$ did not change much the reverse transformation temperatures (as results from Table 1), this aging time was chosen to investigate the effect of aging on the microstructure and superelastic properties of the fabricated element as in this time period the main changes produced by aging already occurred, and it provides a state quite different from the $\mathrm{AD}$ one.

\subsection{Mechanical Properties}

Figure 7 shows the tensile stress/strain curves registered at RT during the loading/unloading of samples of as-deposited part taken from three different directions-deposition direction (DD), built direction (BD), and perpendicular direction (PD). All the samples show a superelastic response. A recoverable strain of about 3\% was observed for samples loaded in PD and $\mathrm{BD}$. On the other hand, the highest recoverable strain of about $3.5 \%$ is exhibited by the sample deformed along the deposition direction. This sample possessed also the highest critical stress for the stress-induced martensitic transformation $\left(\sigma_{\text {SIMT }}\right)$ of 420 $\mathrm{MPa}$. Once the stress exceeds the $\sigma_{\text {SIMT }}$, deformation proceeds at a constant stress for all materials, indicating the formation of stress-induced martensite. However, when the strain reached about $2 \%$, the stress began to increase for BD and PD samples, which may be associated with plastic deformation. On the other hand, the deformation of BD sample took place at near constant stress of 450-500 $\mathrm{MPa}$ up to $4 \%$ elongation. Due to the reverse transformation to the austenite during the unloading, the samples partially recovered their original shape; however, $1 \%$ of permanent deformation for PD and BD samples and $0.5 \%$ for DD one remained after subtracting the tension. Similar behavior was observed in other Ni-rich NiTi alloys fabricated using the additive manufacturing techniques, e.g., recoverable strains in the range of $2-3 \%$ were reported by Wang et al. (Ref 28) for WAAM-manufactured materials. On the other hand, the alloys fabricated using the powder-based methods typically exhibited $A_{f}$ temperature above RT and only partial strain recovery (Ref 17, 18). Slightly higher strain recovery was observed in (Ref 38), however, measured using stress-strain indentation curves. In the same work, tensile curves have shown a similar value of plateau formation near $600 \mathrm{MPa}$ for samples prepared using the AM method. In the present case, the $A_{f}$ temperature of as-deposited alloy $\left(20^{\circ} \mathrm{C}\right)$ resulted in the presence of the superelastic effect at RT, without any additional heat treatment. As the best superelastic response was observed for samples loaded in the deposition direction, more detailed investigations were conducted for samples prepared in this direction. The unusually low value of the Young's modulus of the martensite phase appearing in material property tables $(<40 \mathrm{GPa})$ is generally ascribed in the literature to the fact that stress-driven martensitic transformation and/or twinning processes continue even beyond the transformation range and effectively decrease the value of the tangent modulus (Ref 39).

In the case of the material aged at $500{ }^{\circ} \mathrm{C}$ for $2 \mathrm{~h}$, the formation of martensite occurs at a significantly lower stress, of about $50 \mathrm{MPa}$ as shown in Fig. 8(a). This is associated with a lower energy required for the stress-induced martensitic transformation as a result of higher $M_{s}$ temperature $\left(6^{\circ} \mathrm{C}\right)$ for this alloy in comparison with the as-deposited sample $\left(-10{ }^{\circ} \mathrm{C}\right)$. The formation of the martensite takes place during the deformation at low stress, at about 100-200 MPa; however, close to $\sim 2.5 \%$ the stress begins to increase gradually. This indicates the formation of new variants of martensite or reorientation of already created variants. After unloading only a partial strain recovery was observed, what suggests partial reorientation and stabilization of martensite. Since the reverse transformation temperatures were higher than RT $\left(M_{s}=29^{\circ} \mathrm{C}\right.$ and $M_{f}=48{ }^{\circ} \mathrm{C}$ ), the reverse transformation to the austenite cannot take place during unloading. In order to evaluate the influence of the applied heat treatment on the superelastic properties of the fabricated part, the measurements were also taken at the temperature of $10^{\circ} \mathrm{C}$ above the $A_{f}$ temperature (at $58^{\circ} \mathrm{C}$ ). As can be seen in Fig. 8b, the material exhibited the superelastic effect at this temperature range, with recoverable strain of about $3.5 \%$. Similar values were observed previously for the material in the as-deposited state; however, it is worth noticing that the aging resulted in the increase of the $\sigma_{\text {SIMT }}$ from $420 \mathrm{MPa}$ to $490 \mathrm{MPa}$.

\subsection{In Situ Deformation Studies}

Figure 9 shows tensile stress-strain curves registered during the in situ deformation experiments in SEM of NiTi samples in the as-deposited state and after aging at $500{ }^{\circ} \mathrm{C}$ for $2 \mathrm{~h}$. The points (M1 and M2) marked in the graph indicate where the tensile process was interrupted and the EBSD measurements were taken. Those points correspond to the elongation of $4 \%$ and $7.5 \%$, respectively. The maximum elongation was greater than that in the previous samples (Fig. 7); however, it can be associated with a different method of strain measurement. In the case of the tensile machine, it can be noticed that the maximum elongation was higher as compared with the previously used in the macroscopic analysis of the superelastic properties of the materials (Fig. 7); however, this can be associated with a different method of strain measurement. In the case of the tensile machine, the strain was precisely calculated using the video extensometer. This was impossible in the case of in situ deformation measurements due to a limited space of the vacuum chamber within the SEM; therefore, the
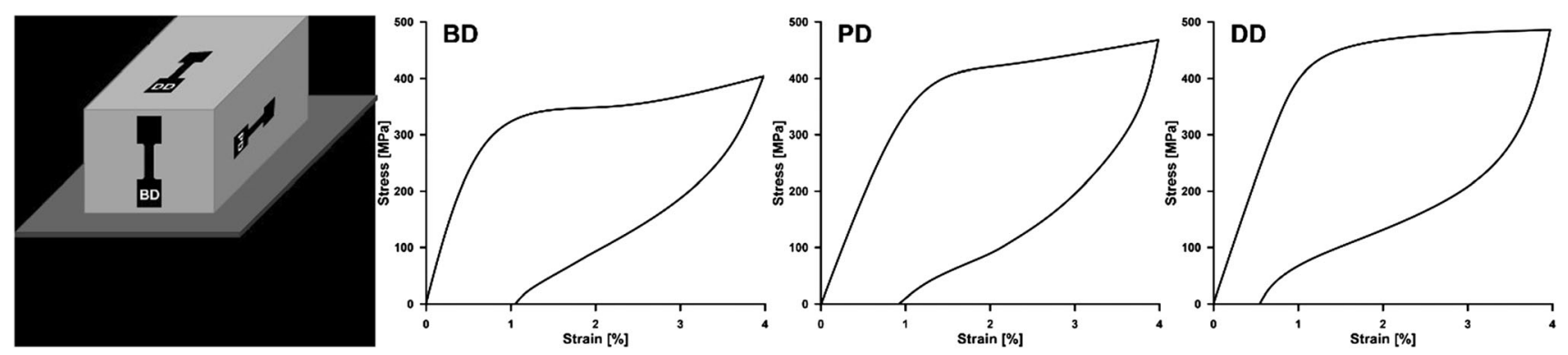

Fig. 7 Tensile stress-strain curves of samples in the as-deposited state measured at RT in three different directions as marked in the scheme 

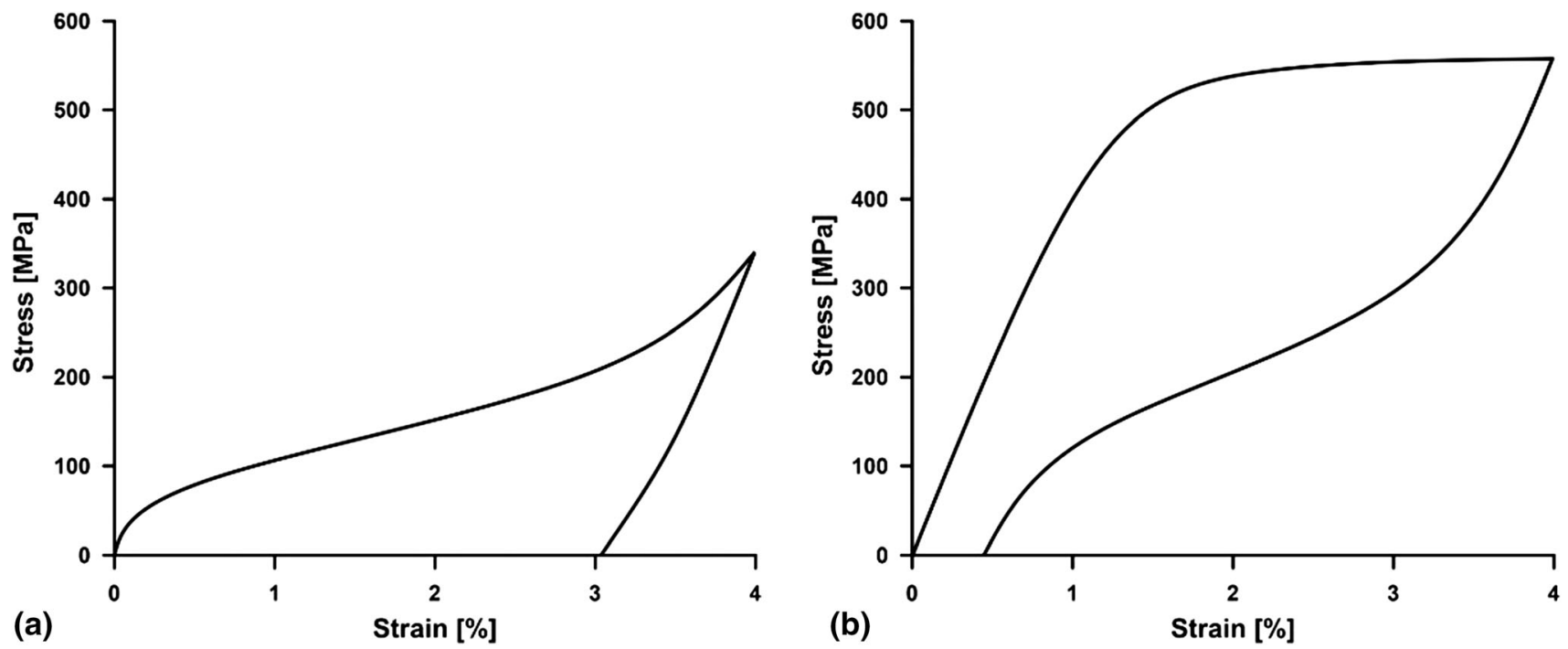

Fig. 8 Tensile stress-strain curves of (a) sample aged at $500{ }^{\circ} \mathrm{C}$ for $2 \mathrm{~h}$ at RT and (b) tested at $58^{\circ} \mathrm{C}\left(10^{\circ} \mathrm{C}\right.$ above Af)

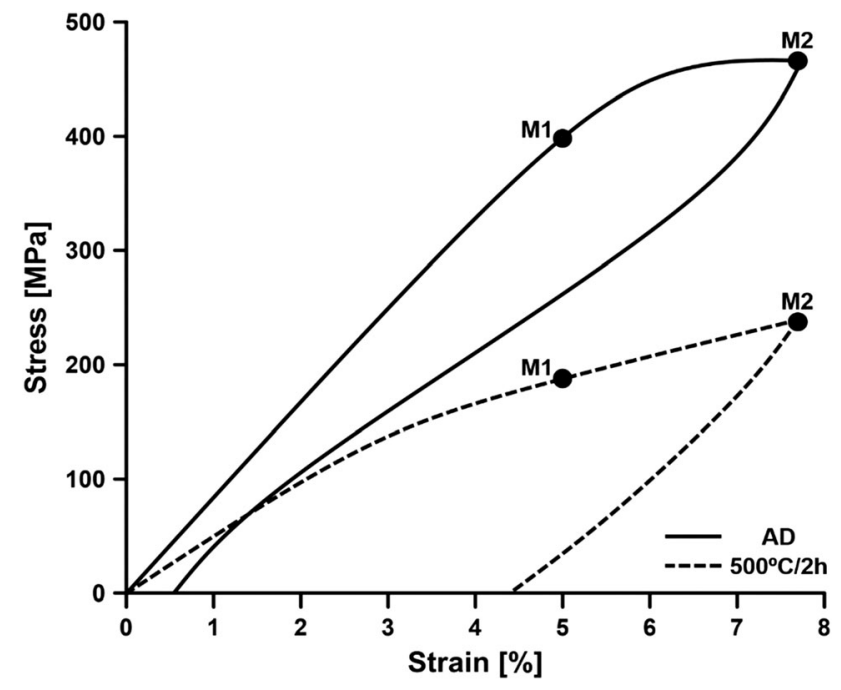

Fig. 9. Tensile stress-strain curves registered during the in situ deformation experiments in SEM, with marked points of the EBSD measurements

presented strain values show a certain measurements error due to the unmeasurable extension of the tensile equipment. The measurement points were selected in such a way to observe the initial stage of martensite formation (M1) and a higher degree of deformation where start of plateau in the tensile curve (M2) can be seen during in situ deformation.

Figure 10 shows the inverse pole figures IPF maps of the asdeposited material acquired during the in situ deformation studies. The sample in the initial state showed only the austenitic microstructure with columnar grains elongated into the direction perpendicular to deposition direction. At a certain degree of deformation, the martensitic needles appear inside those grains. Initially, when the strain reached 4\%, a few larger plates were observed (Fig. 10b). Those plates grow in two different directions indicating the formation of two different martensite variants during deformation. Hereafter, the martensite variant visible as blue is marked as $\mathrm{V} 1$ and visible as green V2. It is also important to note that the V1 variants are nearly perpendicular to the tensile direction, whereas the V2 ones are tilted of about $45^{\circ}$, to attain the maximum shear stress value in agreement with the Schmid law, as found in the in situ studies of conventional superelastic NiTi alloys [46]. When the strain increased up to $7.5 \%$ (Fig. 10c and Fig. 10e), the density of the martensite plates increased and formation of a new fine plates, as well as broadening of the previously formed ones, was observed. In order to determine the orientation relationship between the austenite and the martensite and between the martensite variants, more detailed orientation analysis was performed in the rectangular area marked in Fig. 10c.

Figure 11a shows the IPF map of the selected area of the sample deformed to $7.5 \%$. Figure $10(\mathrm{~b}-\mathrm{d})$ presents maps for each of analyzed component (austenite and two variants of martensite) being the base for the calculated pole figures (PF) corresponding to the visible area and tensile direction marked in Fig. 11. The analysis of (100)B2 and (100)B19' V1 pole figures revealed that the $(100)_{\mathrm{B} 2}$ crystallographic plane of the austenite is parallel to the $(100)_{\mathrm{B} 19^{\prime}}$ plane of the martensite due to overlapping of the corresponding poles in the (100) PF of austenite and (100) PF of the martensite (marked by red circles). Furthermore, the other PFs indicate also the presence of other variants of crystallographic relationship manifested by identical poles position in the corresponding $\mathrm{PF}$ of the martensite and austenite, such as $(100)_{\mathrm{B} 2} \|(011)_{\mathrm{B} 19^{\prime}}$; $(011)_{\mathrm{B} 2} \|(001)_{\mathrm{B} 19^{\prime}}$ and $(011)_{\mathrm{B} 2} \|(11 \overline{1})_{\mathrm{B} 19^{\prime}}$ as also previously observed for the conventionally fabricated NiTi alloys (Ref 3941). The analysis of the IPF maps revealed also the formation of extremely fine twins within the primary needles at higher deformation. This is especially well visible in the case of V2 variant (Fig. 11d), where the group of parallel bands are deflected about $40^{\circ}$ with respect to the primary needle. The analysis of V1 and V2 PF variants indicates the presence of the invariant (11 $\overline{1})$ plane common for both variants (marked in black and showing identical positions in $11 \overline{1}$ PF B19'V1 and B19'V2). Its pole position in (11 $\overline{1})$ PF matches the direction of the twins walls in Fig. 11d. This suggests the presence of type I (11 $\overline{1}$ ) invariant twin boundary as observed earlier for B19' martensite, for example, by Otsuka et al. (Ref 42). In type I twinning, the $K_{1}$ plane and $\eta_{2}$ direction are represented by rational indices and two twin crystals are related by mirror 

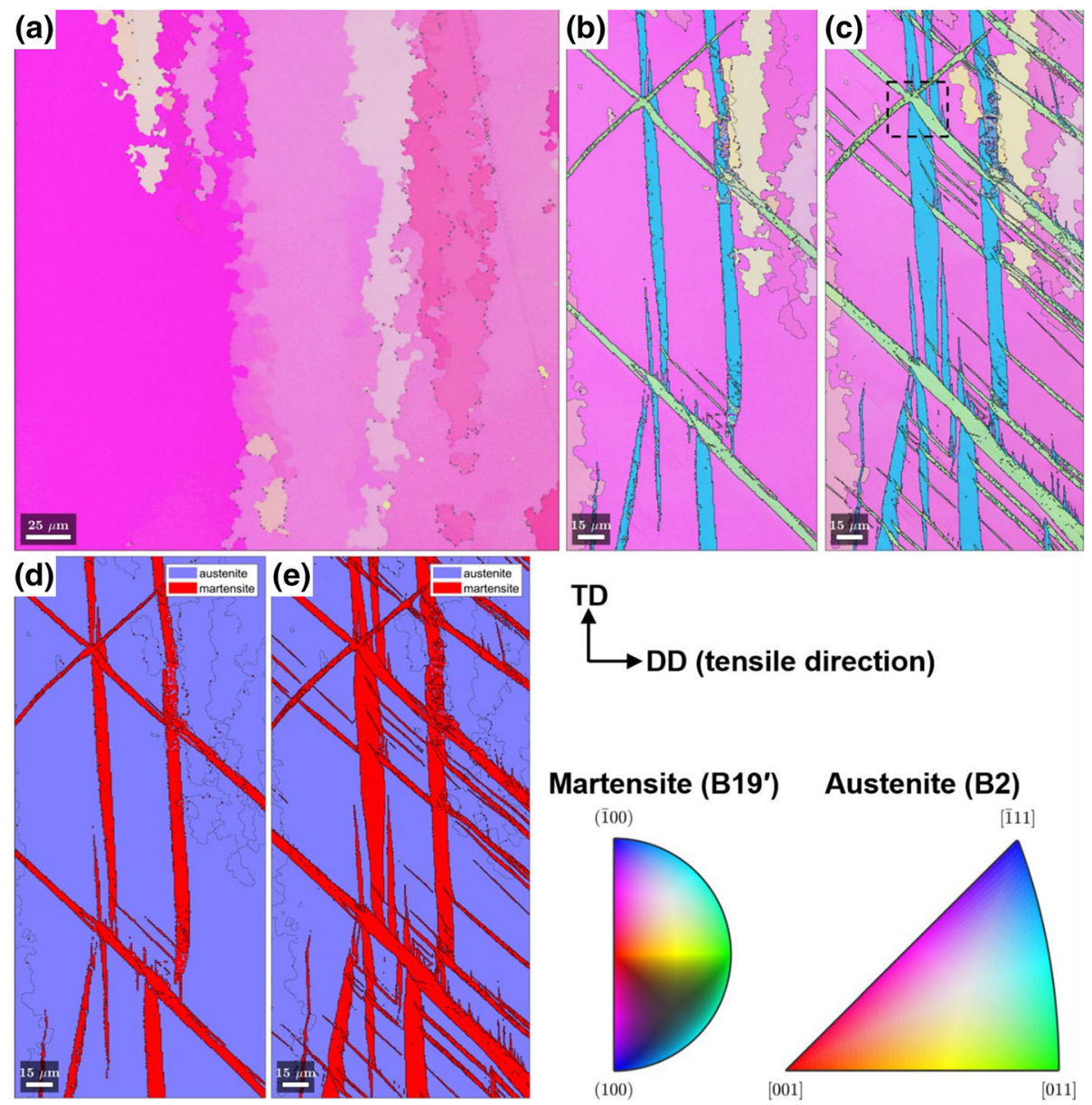

Fig. 10 IPF maps of the as-deposited sample in the initial state (a) and after the deformation to $4 \%$ (b) and $7.5 \%$ (c) and corresponding phase maps of sample deformed to $4 \%$ (d) and $7.5 \%$ (e)

symmetry with respect to the $K_{1}$ plane (Ref 42$)$. $\left\{\begin{array}{lll}1 & 1 & 1\end{array}\right\}$ type of twinning was also observed in (Ref 43) inside SLM-fabricated NiTi due to the presence of precipitated particles and dislocation pile-ups leading to the uneven thickness and chaotic arrangement of twinning lamellae. Similar microstructure was observed in the case of the twinned martensite in the present work. Twinning may be induced at early stages of plastic deformation of martensite; Ezaz et al. (Ref 44) showed the $\{20 \overline{1}\}$ martensite twinning induced at early stages of plastic deformation, while $\{113\}$ martensite twinning occurs at later stages of deformation (Ref 45). Polatidis et al. (Ref 46) reported in situ studies of conventional superelastic NiTi alloys where formation of either $\{112\}$ austenite twins inherited from $\{113\}$ martensite twins (Ref 44 ) or $\{114\}$ austenite twins inherited from \{20 $\overline{1}$ martensite twins was observed during unloading. No such phenomenon was observed during the present work; however, no detailed studies were performed after unloading where only retransformation B19'-B2 was observed. One should, however, consider a very fine size of martensite twins as can be seen in Fig. 11d, which makes more difficult in identification of retransformation austenite twins.

Figure 12 shows the IPF maps registered during the in situ tensile experiment for the sample aged at $500{ }^{\circ} \mathrm{C}$ for $2 \mathrm{~h}$. The material in the initial state exhibited a fully austenitic microstructure. However, by increasing the degree of deformation the formation of martensite needles may be observed. The majority of them are tilted about $45^{\circ}$ with respect to the tensile direction. However, also the needles inclined about $80-85^{\circ}$ may be observed in the grain with the orientation close to [001]. Unfortunately, the quality of the Kikuchi diffraction patterns obtained from the martensite was much worse in comparison with the as-deposited sample, which resulted in their poor solvability. This may be related to the presence of the fine $\mathrm{Ni}_{3} \mathrm{Ti}_{4}$ precipitations, which are typically observed in the aged NiTi alloys, and a high density of defects (Ref 36). These precipitations create internal stress fields causing poor quality of the Kikuchi diffraction patterns from the matrix and may affect also the growth and density of defects in the martensite variants (Ref 47). Furthermore, the needles formed during the deformation of the aged sample, with thickness below $2 \mu \mathrm{m}$, are thinner in comparison with those observed in as-deposited material $(2-10 \mu \mathrm{m})$.

In order to investigate the crystallographic relationships between the martensite and the austenite in the aged material, a more detailed analysis was performed for the sample deformed to $7.5 \%$ in the area shown in Fig. 13. Considering the IPF maps presented in Fig. 13, it can be clearly seen that the martensite plates formed during the deformation are composed of two different parts with various orientations, which are most probably the primary band and the twins. However, the austenite may still be found between them. Based on the calculated PFs for each component, the following groups of parallel planes between the austenite and the martensite may be found: $(100)_{\mathrm{B} 2}\left\|(100)_{\mathrm{B} 19^{\prime}},(100)_{\mathrm{B} 2}\right\|(011)_{\mathrm{B} 19^{\prime}},(011)_{\mathrm{B} 2} \|(001)_{\mathrm{B} 19^{\prime}}$ and 

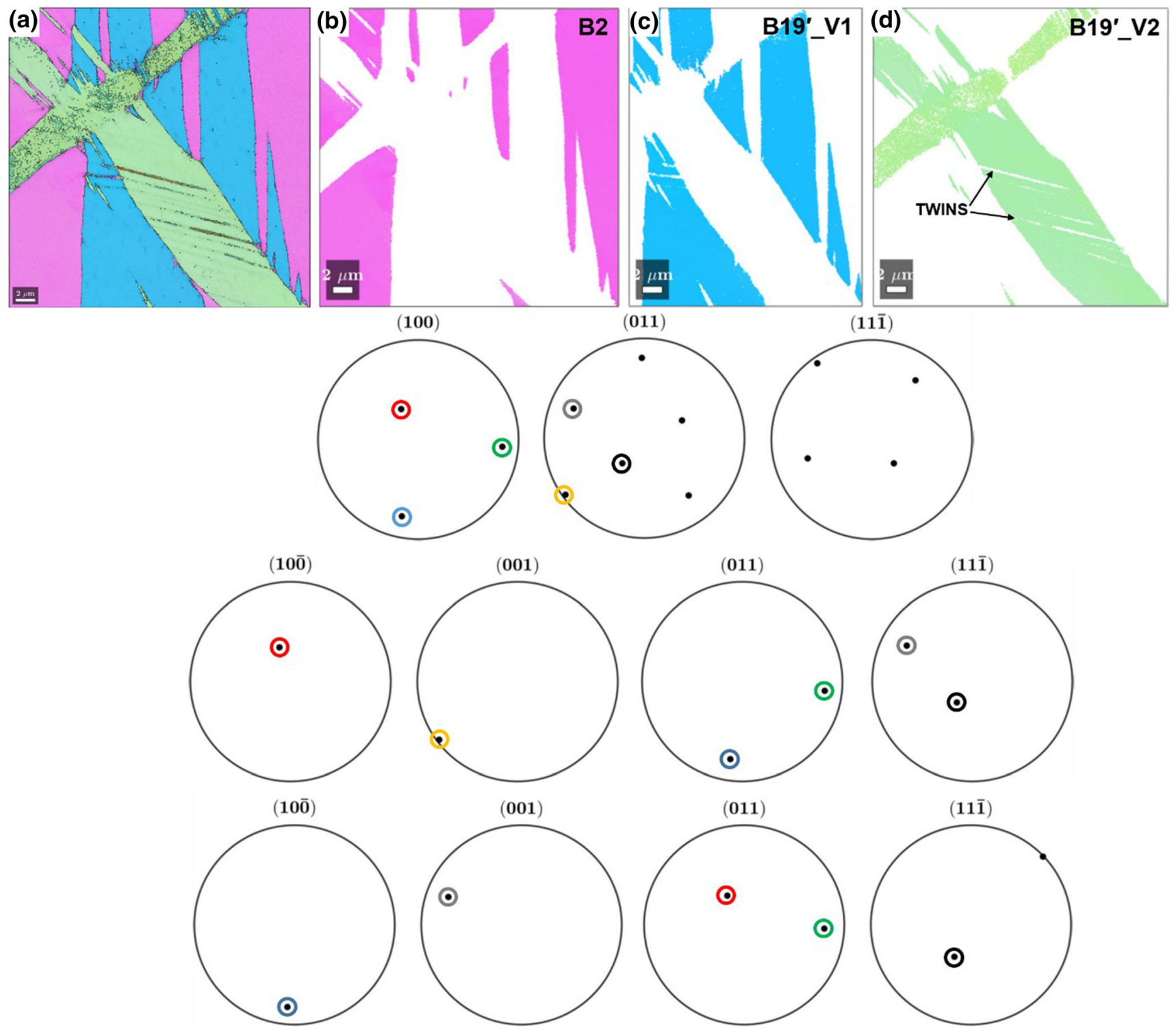

Fig. 11 IPF maps of the selected area of the as-deposited sample deformed to 7.5\% (whole map (a), austenite (b), first martensite variant (c) and second martensite variant (d)) and the corresponding PFs from the area visible in (a-d). The austenite and martensite color-coded triangles are included in Fig. 10.

$(011)_{\mathrm{B} 2} \|(11 \overline{1})_{\mathrm{B} 19^{\prime}}$. The same orientation relationships were previously observed for the as-deposited sample. The IPF images of martensite plates in a twin orientation are not very clear since only some points could be indexed due to stresses arising during phase transition and causing broadening of diffraction lines. The analysis of the second orientation present in the needles in the IPF maps and their pole positions in PFs revealed the twin relationship within the primary band, due to the presence of the invariant (11) pole position common for the yellow and black poles in the (11) PFs of B19' matrix and the twin orientations. The twinning plane observed in Fig. 11d confirms earlier suggestion of Otsuka (Ref 42) of the presence of type I (11 1 ) invariant twin boundary. Although this junction plane was previously reported in the literature (Ref 43), other studies showed other junction planes, such as $(001)_{B 19^{\prime}},(100)_{B 19^{\prime}}$, or $(011)_{B 19^{\prime}}$ (Ref 39, 43).

\section{Conclusions}

1. Application of the EBAM additive manufacturing method allowed to obtain good quality material consisting of columnar grains elongated into the built direction growing directly from the substrate which is related to the epitaxial grain growth mechanism.

2. The martensite transformation peaks observed in DSC studies for the as-deposited material were diffused over the temperature range from -10 to $44{ }^{\circ} \mathrm{C}$; however, with increasing aging time they moved to higher temperatures and became sharper. After 30 -min annealing at $500{ }^{\circ} \mathrm{C}$ the thermal effects observed during cooling were split into two distinct parts. The first one occurred in the temperature range $10-25^{\circ}$ resulting from the R-phase forma- 

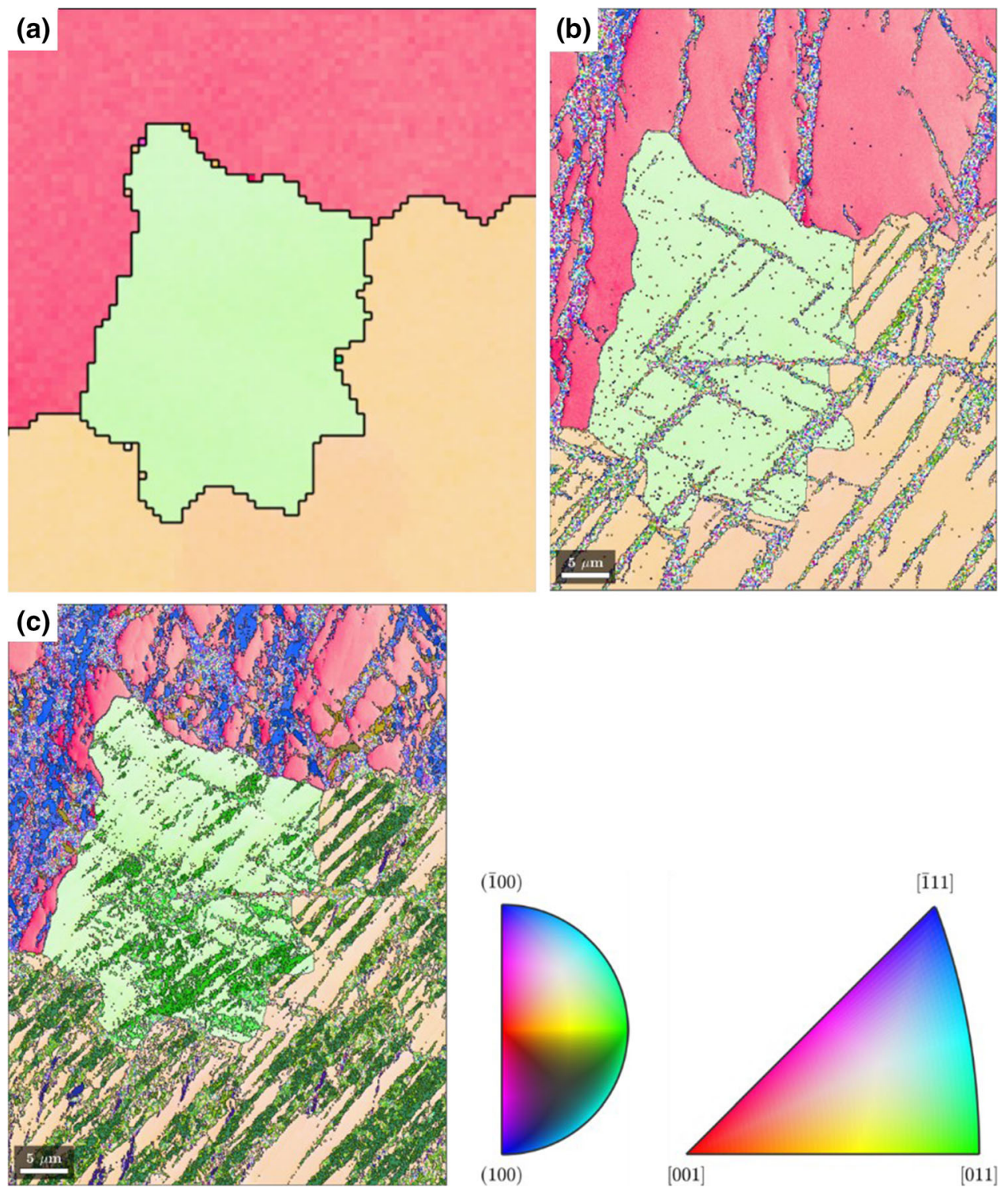

Fig. 12 IPF maps of the sample aged at $500{ }^{\circ} \mathrm{C}$ for $2 \mathrm{~h}$ in the initial state (a), after the deformation to $4 \%$ (b), and $7.5 \%$ (c)

tion, which was commonly observed for the aged Ni-rich NiTi alloys.

3. The highest recoverable strain of about $3.5 \%$ is exhibited by the as-deposited sample (AD) deformed along the deposition direction. In the case of deformation of the alloy aged at $500{ }^{\circ} \mathrm{C}$ for $2 \mathrm{~h}$, the formation of martensite occurs at significantly lower stress; however, at about $2.5 \%$ the stress begins to increase gradually and only a small part of shape recovery was observed, which suggests the deformation of martensite and possible shape recovery at higher temperatures. At temperature of $10{ }^{\circ} \mathrm{C}$ above $\mathrm{A}_{\mathrm{f}}$, the material exhibited the superelastic effect, with recoverable strain of about $3.5 \%$, similar to the AD alloy.

4. In situ SEM observation of the austenitic columnar grains elongated in the direction perpendicular to deposition direction showed that the martensite began to appear in- side those grains under an angle of $45^{\circ}$ with increasing deformation degree, in agreement with the Schmid law. Obtained results indicated the following crystallographic relationships between $\mathrm{B} 2$ and $\mathrm{B} 19^{\prime}$ martensite: $(100)_{\mathrm{B} 2} \|(100)_{\mathrm{B} 19}$, and (100) B2 $\|(011)_{\mathrm{B} 19^{\prime} ;}$ (011)B2\| $(001)_{\mathrm{B} 19}$, and $(011)_{\mathrm{B} 2} \|(11 \overline{1})_{\mathrm{B} 19^{\prime}}$ already observed in the conventionally fabricated NiTi alloys. Samples aged at $500{ }^{\circ} \mathrm{C}$ for $2 \mathrm{~h}$ exhibited fully austenitic microstructure; however, with increasing deformation degree the formation of martensite was observed. The majority of needles are tilted of about $45^{\circ}$ with respect to the tensile direction; however, also needles inclined at about $80-85^{\circ}$ may be observed in grains with orientation close to [001]. The presence of type I (11 $\overline{1})$ invariant twin boundaries was observed at higher degrees of deformation confirming earlier observation of Otsuka for B19' martensite. 

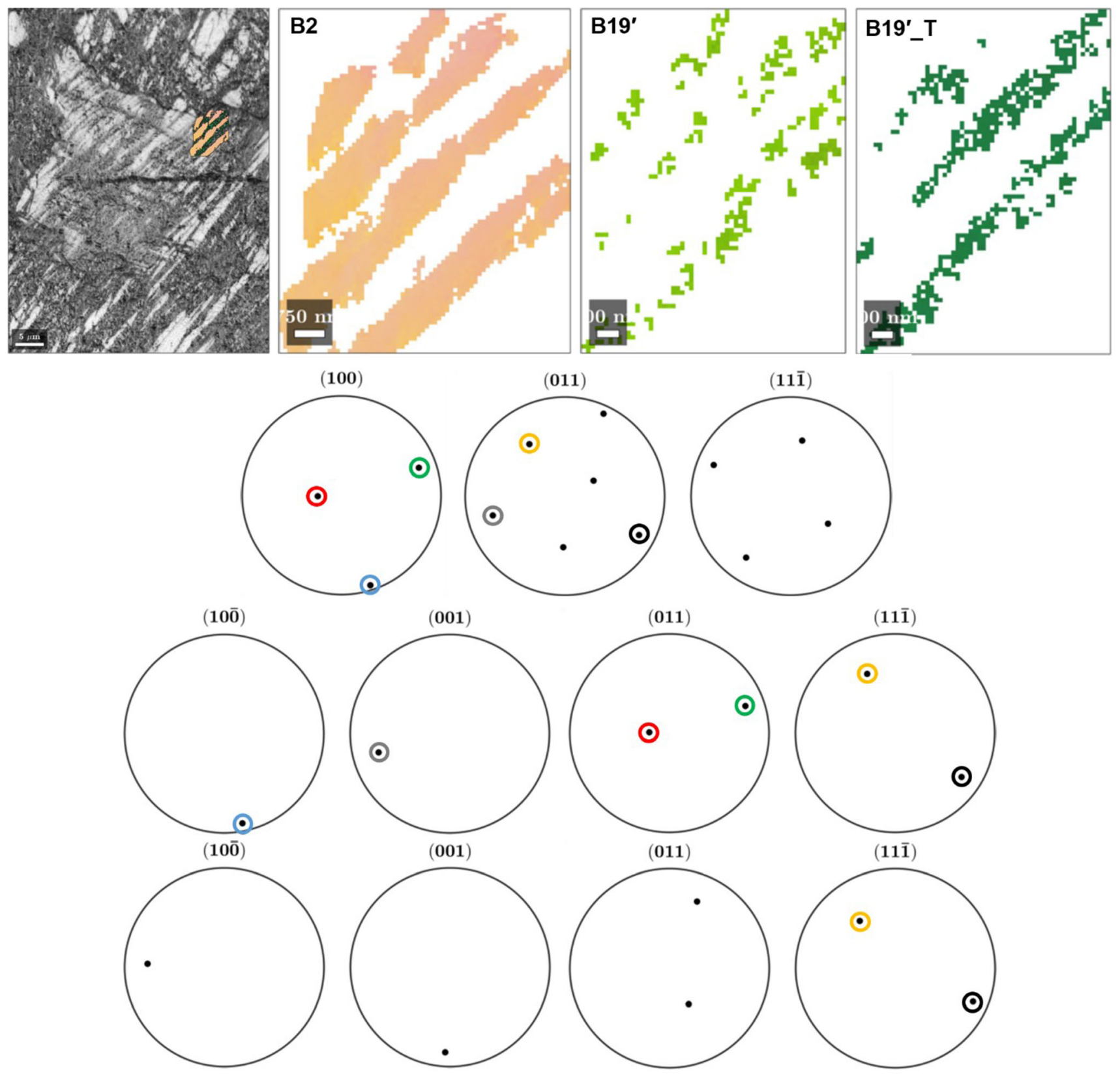

Fig. 13. IPF maps of the selected area of the aged sample deformed to $7.5 \%$. The following components are presented: austenite (B2), primary

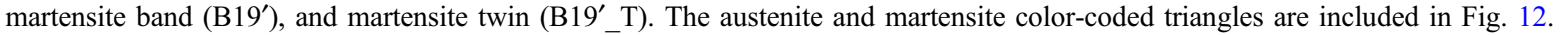

\section{Acknowledgments}

The presented research results are the effect of the project no. UMO-2016/23/B/ST8/00754 financed by the National Science Center, Poland. The authors are grateful to Dr. M. Chandrasekaran from SMATEC Company, Belgium, for valuable discussions and supplying the NiTi wire and support sheets. Partial financial support from AEIEU FEDER (project RTI2018-094683-B-C51) is acknowledged.

\section{Open Access}

This article is licensed under a Creative Commons Attribution 4.0 International License, which permits use, sharing, adaptation, distribution and reproduction in any medium or format, as long as you give appropriate credit to the original author(s) and the source, provide a link to the Creative Commons licence, and indicate if changes were made. The images or other third party material in this article are included in the article's Creative Commons licence, unless indicated otherwise in a credit line to the material. If material is not included in the article's Creative Commons licence and your intended use is not permitted by statutory regulation or exceeds the permitted use, you will need to obtain permission directly from the copyright holder. To view a copy of this licence, visit http://creativecommons.org/licenses/by/4.0/.

\section{References}

1. L. Lecce, Shape Memory Alloy Engineering for Aerospace, Structural and Biomedical Applications Editors-in-Chief. 2015 
2. T. Yoneyama and S. Miyazaki, Shape Memory Alloys for Biomed. Appl., 2008 https://doi.org/10.1533/9781845695248

3. M. Elahinia, N.S. Moghaddam, M. Taheri Andani, A. Amerinatanzi, B.A. Bimber, R.F. Hamilton, Fabrication of NiTi through Additive Manufacturing: A review, Prog Mater Sci 2016; 83: p 630-663

4. W.E. Frazier, Metal Additive Manufacturing: A Review, J. Mater Eng Perform, 2014, 23, p 1917-1928.

5. C. Wang, X.P. Tan, Z. Du, S. Chandra, Z. Sun, C.W.J. Lim, S.B. Tor, C.S. Lim and C.H. Wong, Additive Manufacturing of NiTi Shape Memory Alloys Using Pre-Mixed Powders, J. Mater. Process. Technol., 2019, 271, p 152-161.

6. R.F. Hamilton, B.A. Bimber and T.A. Palmer, Correlating Microstructure and Superelasticity of Directed Energy Deposition Additive Manufactured Ni-rich NiTi alloys, J. Alloys Compd., 2018, 739, p 712722.

7. J. Dutkiewicz, Ł Rogal, D. Kalita, M. Weglowski, S. Błacha, K. Berent, T. Czeppe, A. Antolak-Dudka, T. Durejko and T. Czujko, Superelastic Effect in NiTi Alloys Manufactured Using Electron Beam and Focused Laser Rapid Manufacturing Methods, J. Mater. Eng. Perform., 2020, 29, p 4463-4473.

8. X. Wang, J. Yu, J. Liu, L. Chen, Q. Yang, H. Wei, J. Sun, Z. Wang, Z. Zhang, G. Zhao, J. Van Humbeeck, Effect of Process Parameters on the Phase Transformation Behavior and Tensile Properties of NiTi Shape Memory Alloys Fabricated By Selective Laser Melting, Addit. Manuf. 2020, 36, 101545

9. J.P. Oliveira, A.J. Cavaleiro, N. Schell, A. Stark, R.M. Miranda, J.L. Ocana and F.M. Bra, Fernandes, Effects of laser processing on the transformation characteristics of NiTi: A contribute to additive manufacturing, Scr. Mater., 2020, 2018(152), p 122-126.

10. S. Saedi, N. Shayesteh Moghaddam, A. Amerinatanzi, M. Elahinia, H.E. Karaca, On the Effects of Selective Laser Melting Process Parameters on Microstructure and Thermomechanical Response of Nirich NiTi, Acta Mater. 2018, 144, p 552-560

11. Q. Zhou, M.D. Hayat, G. Chen, S. Cai, X. Qu, H. Tang and P. Cao, Selective Electron Beam Melting of NiTi: Microstructure, Phase Transformation and Mechanical Properties, Mater. Sci. Eng. A., 2019, 744, p 290-298.

12. J. Gan, L. Duan, F. Li, Y. Che, Y. Zhou, S. Wen, C. Yan, Effect of Laser Energy Density on the Evolution of Ni4Ti3 Precipitate and Property of NiTi Shape Memory Alloys Prepared by selective laser melting, J. Alloys Compd. 2021, 869, 159338

13. C. Haberland, M. Elahinia, J.M. Walker, H. Meier, J. Frenzel, On the Development of High Quality NiTi Shape Memory and Pseudoelastic Parts by Additive Manufacturing, Smart Mater. Struct. 2014, 23 , 104002

14. J. Ma, B. Franco, G. Tapia, K. Karayagiz, L. Johnson, J. Liu, R. Arroyave, I. Karaman and A. Elwany, Spatial Control of Functional Response in 4D-printed Active Metallic Structures, Sci. Rep., 2017, 7, p 1-8.

15. N. Shayesteh Moghaddam, S. Saedi, A. Amerinatanzi, A. Hinojos, A Ramazani, J. Kundin, M.J. Mills, H. Karaca, M. Elahinia, Achieving Superelasticity in Additively Manufactured $\mathrm{NiTi}$ in Compression Without Post-Process Heat Treatment, Sci. Rep. 2019, 9, p 1-11

16. S. Saedi, A.S. Turabi, M.T. Andani, C. Haberland, H. Karaca and M. Elahinia, The Influence of Heat Treatment on the Thermomechanical Response of Ni-rich NiTi Alloys Manufactured by Selective Laser Melting, J. Alloys Compd., 2016, 677, p 204-210.

17. S. Saedi, A.S. Turabi, M.T. Andani, N.S. Moghaddam, M. Elahinia and H.E. Karaca, Texture, aging, and Superelasticity of Selective Laser Melting Fabricated Ni-rich NiTi alloys, Mater. Sci. Eng. A., 2017, 686, p 1-10.

18. N. Shayesteh Moghaddam, S.E. Saghaian, A. Amerinatanzi, H Ibrahim, P. Li, G.P. Toker, H.E. Karaca, M. Elahinia, Anisotropic Tensile and Actuation Properties of NiTi Fabricated with Selective Laser Melting, Mater. Sci. Eng. A. 2018, 724, p 220-230

19. C. Haberland, H. Meier, J. Frenzel, On the Properties of Ni-rich NiTi Shape Memory Parts Produced by Selective Laser Melting, in: ASME 2012 Conf. Smart Mater. Adapt. Struct. Intell. Syst. SMASIS 2012, American Society of Mechanical Engineers Digital Collection, 2012: pp. 97-104. https://doi.org/10.1115/SMASIS2012-8040

20. K.S. Derekar, A Review of Wire arc Additive Manufacturing and Advances in Wire arc Additive Manufacturing of Aluminium, Mater Sci. Technol., 2018, 34, p 895-916.
21. K.N. Kalashnikov, V.E. Rubtsov, N.L. Savchenko, T.A. Kalashnikova, K.S. Osipovich, A.A. Eliseev and A.V. Chumaevskii, The Effect of Wire Feed Geometry on Electron Beam Freeform 3D Printing of Complex-Shaped Samples from Ti-6Al-4V Alloy, Int. J. Adv. Manuf. Technol., 2019, 105, p 3147-3156.

22. W. Yangfan, C. Xizhang and S. Chuanchu, Microstructure and Mechanical Properties of Inconel 625 Fabricated by Wire-arc Additive Manufacturing, Surf. Coatings Technol., 2019, 374, p 116-123.

23. S.Y. Tarasov, A.V. Filippov, N.L. Savchenko, S.V. Fortuna, V.E. Rubtsov, E.A. Kolubaev and S.G. Psakhie, Effect of Heat Input on Phase Content, Crystalline Lattice Parameter, and Residual Strain in Wire-Feed Electron Beam Additive Manufactured 304 Stainless Steel, Int. J. Adv. Manuf. Technol., 2018, 99, p 2353-2363.

24. D. Ding, Z. Pan, D. Cuiuri and H. Li, Wire-Feed Additive Manufacturing of Metal Components: Technologies, Developments and Future Interests, Int. J. Adv. Manuf. Technol., 2015, 81, p 465-481.

25. https://www.sciaky.com/additive-manufacturing/wire-vs-powder, (n.d.)

26. J. Wang, Z. Pan, G. Yang, J. Han, X. Chen and H. Li, Mater. Sci. Eng. A., 2019, 749, p 218-222.

27. Z. Zeng, B.Q. Cong, J.P. Oliveira, W.C. Ke, N. Schell, B. Peng, Z.W. Qi, F.G. Ge, W. Zhang, S.S. Ao, Wire and arc Additive Manufacturing of a Ni-rich NiTi Shape Memory Alloy: Microstructure and mechanical properties, Addit. Manuf. 2020, 32, 101051

28. J. Wang, Z. Pan, Y. Wang, L. Wang, L. Su, D. Cuiuri, Y. Zhao, H. Li, Evolution of Crystallographic Orientation, Precipitation, Phase Transformation and Mechanical Properties Realized by Enhancing Deposition Current for Dual-Wire Arc Additive Manufactured Ni-rich NiTi alloy, Addit. Manuf. 2020, 34, 101240

29. N.Resnina, I.A.Palani, S.Belyaev, P.Liulchak, U.Karaseva, M.Manikandan, S. Jayachandran, V. Bryukhanova, A. Sahu, R. Bikbaev, Structure, Martensitic Transformations and Mechanical Behaviour of NiTi Shape Memory Alloy Produced by Wire arc Additive Manufacturing, J. Alloys Compd. 2021, 851, 156851

30. J. Mentz, M. Bram, H.P. Buchkremer and D. Stöver, Improvement of Mechanical Properties of Powder Metallurgical NiTi Shape Memory Alloys, Adv. Eng. Mater, 2006, 8, p 247-252.

31. M. Speirs, X. Wang, S. Van Baelen, A. Ahadi, S. Dadbakhsh, J.P. Kruth and J. Van Humbeeck, On the Transformation Behavior of NiTi Shape-Memory Alloy Produced by SLM, Shape Mem., 2016, 2, p 310 316

32. T. Wang, Y.Y. Zhu, S.Q. Zhang, H.B. Tang and H.M. Wang, Grain Morphology Evolution Behavior of Titanium Alloy Components during Laser Melting Deposition Additive Manufacturing, J. Alloys Compd., 2015, 632, p 505-513.

33. K. Otsuka, Crystallography of Martensitic Transformation and type II Twinning, Proc. Int. Conf. Martensitic Transform. ICOMAT86 ed. Japan Inst Metals 1986, p 35-42

34. M. Nishida and C.M. Wayman, I R-phase type Transformation of $\mathrm{Ti}_{2} \mathrm{Ni}_{3}$ Precipitates in aged Ti52at.\% Ni, Proc. Int. Conf. Martensitic Transform. ICOMAT86 ed. Japan Inst Metals 1986, p 653-658

35. X.B. Wang, B. Verlinden and J. Van Humbeeck, R-phase Transformation in NiTi alloys, Mater. Sci. Technol., 2014, 30, p 1517-1529.

36. J. Khalil-Allafi, A. Dlouhy and G. Eggeler, Ni4Ti3-Precipitation during aging of NiTi Shape Memory Alloys and its Influence on Martensitic Phase Transfor Mations, Acta Mater., 2002, 50, p 4255-4274.

37. X. Wang, B. VerlinDen and S. Kustov, Multi-stage Martensitic Transformation in Ni-rich NiTi Shape Memory Alloys, Funct. Mater. Lett., 2017, 10, p 1740004

38. P. Šittner, L. Heller, J. Pilch, C. Curfs, T. Alonso et al., Young's Modulus of Austenite and Martensite Phases in Superelastic NiTi Wires, Journal of Materials Engineering and Performance, Springer Verlag/ASM International, 2014, 23(7), p 2303-2314.

39. S.C. Mao, J.F. Luo, Z. Zhang, M.H. Wu, Y. Liu and X.D. Han, EBSD Studies of the Stress-induced B2-B19' Martensitic Transformation in NiTi Tubes under Uniaxial Tension and Compression, Acta Mater, 2010, 58, p 3357-3366.

40. C. Cayron, What EBSD and TKD tell us about the Crystallography of the Martensitic B2-B19' Transformation in Niti shape Memory Alloys, Curr. Comput.-Aided Drug Des., 2020, 10, p 1-33.

41. S. Miyazaki and C.M. Wayman, The Shape Memory Mechanism Associated with the R-Phase Transitionin NiTi Single Crystals Proc. Int. Conf. Mart. Transf. 1986 Ed. The Japan Institute of Metals 1986, p.665-670 
42. K. Otsuka, T. Sawamura and K. Shimizu, Crystal Structure and Internal Defects of Equiatomic TiNi Martensite, Phys. Status Solidi., 1971, 5, p 457-470.

43. Qingquan Zhang, Shijie Hao, Yuting Liu, Zhiwei Xiong, Wenqian Guo, Ying Yang, Yang Ren, Lishan Cui, Luquan Ren, Zhihui Zhang, The Microstructure of a Selective Laser Melting (SLM)-Fabricated NiTi shapememory Alloy with Superior Tensile Property and Shape Memory Recoverability, Applied Materials Today 19 (2020) 100547

44. T. Ezaz, H. Sehitoglu,W. Abuzaid, H.J.Maier, Higher order twin modes in martensitic NiTi-the (2011) case, Mater. Sci. Eng. A 2012, 558, p 422-430,

45. I. Karaman, A.V. Kulkarni and Z.P. Luo, Transformation Behaviour and Unusual Twinning in a NiTi Shape Memory Alloy Ausformed using Equal Channel Angular Extrusion, Philos. Mag., 2005, 85, p 1729-1745.

46. E. Polatidis, M. Šmíd, I. Kuběna,W.-N. Hsu, G. Laplanche, H. Van Swygenhoven, Deformation Mechanisms in a Superelastic NiTi Alloy: An in-situ High Resolution Digital Image Correlation Study, Materials and Design 2020, 191, 108622

47. Z. Yang, W. Tirry, D. Lamoen, S. Kulkova and D. Schryvers, Electron Energy-Loss Spectroscopy and First-Principles Calculation Studies on a Ni-Ti shape Memory Alloy, Acta Mater, 2008, 56, p 395-404.

Publisher's Note Springer Nature remains neutral with regard to jurisdictional claims in published maps and institutional affiliations. 